\title{
Evaluation of endocrine and cardiac complications in survivors of childhood acute lymphoblastic leukemia: A single center study from south Punjab.
}

1. MBBS, DCH, FCPS (Paediatrics) Associate Professor Paediatric Endocrinology

The Children Hospital \& The Institute of Child Health, Multan.

2. MBBS, DCH, FCPS (Paediatrics) Assistant Professor Paediatric Hematology-oncology The Children Hospital \& The Institute of Child Health, Multan.

3. MBBS, DCH, FCPS (Paediatrics) FCPS (Paediatric Cardiology) Associate Professor Paediatric Cardiology

The Children Hospital \& The Institute of Child Health, Multan.

Correspondence Address:

Dr. Waqas Imran Khan

Department of Paediatric

Endocrinology

The Children Hospital \& The Institute

of Child Health, Multan.

drwaqas69@hotmail.com

Article received on:

01/06/2020

Accepted for publication:

06/08/2020

\begin{abstract}
Waqas Imran Khan', Zulfiqar Ali $^{2}$, Sohail Arshad ${ }^{3}$
ABSTRACT... Objectives: The objective of our study was to evaluate the endocrine and cardiac complications in survivors of childhood ALL. Study Design: Descriptive Cross Sectional study. Setting: Department of Pediatric Hematology-oncology, Endocrinology and Cardiology at The Children Hospital \& Institute of Child health Multan (CH\& ICH). Period: January 2019 to June 2019. Material \& Methods: Sixty patients were enrolled after taking informed consent from patient/parents. Endocrine complications include (growth failure, overweight/obesity, hyperlipidemia, thyroid disorders, precocious puberty) and cardiac complications include hypertension and low ejection fraction were evaluated. Results: Out of 60 ALL survivors 32 were males (53.3\%) and 28 were females (46.7\%). At diagnosis patient's age range was 7-17 years with median age of 11.6 years. At study median age was 17 years with age range of 13 to 23 years. Among our ALL survivors $56.6 \%$ had one complication and $25 \%$ had multiple problems. Obesity $(25 \%)$, overweight $(20 \%)$ and hyperlipidemia $(26.4 \%)$ were the three common complications followed by short stature (5\%), thyroid disorders (3.3\%) and hypertension (3.3\%). Conclusion: We report high prevalence $(56.6 \%)$ of these complications from south Punjab. Therefore extended follow up of ALL survivors is needed in order to identify an abnormality and timely treatment and improved quality of life.
\end{abstract}

Key words: $\quad$ Acute Lymphoblastic Leukemia, Childhood, Cardiac, Endocrine, Late Complications.

Article Citation: Khan WI, Ali Z, Arshad S. Evaluation of endocrine and cardiac complications in survivors of childhood acute lymphoblastic leukemia: A single center study from south Punjab. Professional Med J 2021; 28(1):32-36. https://doi.org/10.29309/TPMJ/2021.28.01.5046

\section{INTRODUCTION}

Acute lymphoblastic leukemia (ALL) is a most frequent malignant disorder in children and occurs due to abnormal proliferation of lymphoid cells. ${ }^{1-3}$ It is estimated that incidence of ALL is 3 per 100000 population globally. ${ }^{4}$ In Pakistan, ALL is the most common malignancy in children. ${ }^{5}$ However due to non availability of national cancer registry in Pakistan, actual incidence is not known. ${ }^{6}$ Due to improvement in treatment protocols and high standards of supportive care, long term survival exceeds $>80 \%{ }^{7}$

About half of ALL survivors experience one or more long term sequel. ${ }^{8}$ These complications may be due to chemotherapeutic agents or cranial irradiation. ${ }^{9}$ High survival rate leads to increase in long term complications especially endocrine, cardiac, neuro-cognitive, and psychosocial problems. ${ }^{10}$ Endocrine complications include metabolic syndrome, short stature due to growth hormone insufficiency, thyroid abnormalities, adrenal insufficiency and bone demineralization.

Cardiac abnormalities include low ejection fraction due to reduced left ventricle wall thickness. This could be due to antracycline toxicity. ${ }^{11}$ Hypertension can occur in childhood ALL survivors, so blood pressure (BP) should be measured on every visit.

The objective of our study was to evaluate the endocrine and cardiac complications in survivors of childhood ALL in our hematology-oncology department treated with UK ALL protocol 2011 version 3.0. 


\section{MATERIAL \& METHODS}

This descriptive cross sectional study was done in department of pediatric hematology-oncology, endocrinology and cardiology at The Children hospital \& Institute of Child health Multan (CH\& ICH) from January 2019 to June 2019. This study was approved by the institutional Ethical committee of the $\mathrm{CH} \& \mathrm{ICH}$, Multan.

Patients were enrolled after taking informed consent from patient/parents according to following criteria: patients will ALL diagnosed in our center between January 2012 to December 2016, at least 2 years have passed after completion of treatment, age $<18$ years at time of diagnosis with no relapse. Sixty patients were enrolled during routine follow up visit.

Diagnosis of ALL was confirmed by bone marrow morphology and immunophenotyping by flowcytometry method. Detailed history was taken including name, age, sex, age at time of diagnosis, type of ALL, initial anthropometric data and echocardiographic findings, treatment protocol used and accumulative steroid and antracycline dose. UK ALL protocol 2011 version $3.0^{12}$ was used to treat all children. This protocol consists of following stages: induction, consolidation, interim maintenance, delayed intensification and maintenance phase. Total cumulative antracycline dose used was $240 \mathrm{mg} /$ $\mathrm{m}^{2}$. Duration of treatment was 30 months for both males and females.

Endocrinological evaluation includes height measurement with Harpenden stadiometer and plotted on centile charts by Center for disease control and prevention (CDC) charts. ${ }^{13}$ Height was noted at the time of diagnosis and study visit. Similarly body mass index (BMI) was calculated as weight in kilogram/height in meter square and plotted on CDC charts. BMI of $>95$ centile were considered as obese and $>85$ to 95 as over-weight. Fasting blood glucose (FBS) and lipid profile were send. FBS of $>126 \mathrm{mg} /$ dl was considered abnormal. Similarly fasting cholesterol \& low density lipoprotein of $>200 \mathrm{mg} /$ $\mathrm{dl}$ and $>130 \mathrm{mg} / \mathrm{dl}$ was considered as high.
Hormonal profile was measured by Chemiluminesence Immunoassay method. Thyroid profile included free T4 (fT4) 0.89-1.76 $\mathrm{ng} / \mathrm{dl}$ and TSH 0.7-6.4 ulU/ml. Bone age was calculated according to Greulich and Pyle atlas. ${ }^{14}$ Puberty was assessed by Tanner staging ${ }^{15}$ method. Precocious puberty ${ }^{16}$ was defined as appearance of secondary sexual characteristics before age 8 $\& 9$ years in girls and boys respectively. Delayed puberty ${ }^{17}$ was defined as no appearance of secondary sexual characteristics after 13 \& 14 years in girls and boys respectively.

Cardiological evaluation was done by pediatric cardiologist. BP was measured in sitting position when the patient was relaxed. Hypertension is defined as blood pressure in the 95th percentile or higher according to age, sex and height. ${ }^{18}$ Chest roentgenogram, electrocardiogram and echocardiography were done. Normal ejection fraction was taken as $60 \%$ or more.

The data was analyzed by Statistical Program for Social Science software (SPSS, Chicago, IL, USA), version 20.0 for windows. Categorical variables were expressed as frequencies and percentages while continuous variables as mean \pm SD. Clinical variables and laboratory tests were assessed by Chi-square test of significance and student's t-test where appropriate. $P$ value of less than or equal to 0.5 was taken as statistically significant.

\section{RESULTS}

Out of 60 ALL survivors 32 were males (53.3\%) and 28 were females $(46.7 \%)$. At diagnosis patient's age range was 7-17 years with median age of 11.6 years. At study median age was 17 years with age range of 13 to 23 years. Majority of survivors, 58 (96.6\%) of patients were suffering from B-cell ALL. At least 2 years have passed after completion of chemotherapy. Baseline characteristics of patients are shown in Table-I.

Among our ALL survivors $56.6 \%$ had one complication and $25 \%$ had multiple problems. Obesity (25\%), overweight (20\%) and hyperlipidemia (26.4\%) were the three common complications followed by short stature $(5 \%)$, 
thyroid disorders (3.3\%) and hypertension (3.3\%) (table2). Cardiac evaluation was normal at the time of diagnosis which consists of physical examination, ECG and echocardiography. At the time of study, hypertension and systolic dysfunction was observed in two patients, one male and one female patient. In both patients cumulative antracycline dose was $240 \mathrm{mg} / \mathrm{m}^{2}$. Fasting blood sugar was normal in all patients, means (90 \pm 8$)$, range 78 to $105 \mathrm{mg} / \mathrm{dl}$.

In this study, relationship of endocrine complications like age, hyperlipidemia, short stature, thyroid disorders and hypertension with respect to weight of patients was assessed (Table-III). Hyperlipidemia was observed more in obese/overweight group (88.3\%) as compared to normal weight children (12.1\%) with p-value of $<0.001$. There was no significant relationship between age, short stature, hypertension and thyroid disorders in relation to overweight/obesity.

\begin{tabular}{|l|c|}
\hline Sex $\mathbf{n}(\%)$ & $32(53.3)$ \\
\hline Male & $28(46.7)$ \\
\hline Female & \\
\hline Median age $\mathbf{n}$ (min-max) & $11.6(7-17)$ \\
\hline At diagnosis & $14(10-20)$ \\
\hline At completion of treatment & $17(13-23)$ \\
\hline At time of study & \\
\hline Leukemia type $\mathbf{n}(\%)$ & \\
\hline B-cell & $02(3.4)$ \\
\hline T-cell & \\
\hline Chemotherapy protocol $\mathbf{n}(\%)$ & $60(100)$ \\
\hline $\begin{array}{l}\text { UK ALL 2011 version 3.0 } \\
\text { Table-I. Baseline characteristics of ALL survivors } \\
(\mathbf{N}=60)\end{array}$ \\
\hline
\end{tabular}

\begin{tabular}{|l|c|}
\hline Overweight & $12(20 \%)$ \\
\hline Obesity & $15(25 \%)$ \\
\hline Hyperlipidemia & $16(26.4 \%)$ \\
\hline Precocious puberty & $01(1.6 \%)$ \\
\hline Short stature & $02(3.3 \%)$ \\
\hline Thyroid disorders & $03(5 \%)$ \\
\hline Hypertension \& low ejection fraction & $02(3.3 \%)$ \\
\hline \multicolumn{2}{|c|}{ Table-II. Endocrine and cardiac effects in All } \\
survivors (N=60)
\end{tabular}

\section{DISCUSSION}

This study was designed to determine the endocrine and cardiac complication in survivors of ALL. Though its survivor rate has increased due to improved treatment regimens and supportive care, still it has high mortality in resource constraint country like Pakistan. ${ }^{19-20}$ In our study $56.6 \%$ had one complication and $25 \%$ had several complications. Oeffinger et al. ${ }^{21}$ reported that among ALL survivors, $62.3 \%$ had one complication.

Overweight/obesity was the most frequent complication in our study, which is in consistent with other studies. ${ }^{22}$ Zhang et. Al. ${ }^{23}$ reported that BMI Z-score and weight at diagnosis were important predictors of obesity at the end of treatment. Hyperlipidemia was observed in 12 (20\%) out of 60 survivors. Most of these patients were obese/overweight as compared to normal weight subjects. Hypothyroidism was detected in $3(5 \%)$ of patients. It had no relationship with weight of patients and none had received cranial irradiation. Precocious puberty was seen in only 1 (1.6\%) patient who was female. However Chow et. Al. ${ }^{24}$ reported normal menarche in ALL survivors.

\begin{tabular}{|c|c|c|c|c|}
\hline Endocrine Complications & $\begin{array}{l}\text { Over Weight } \\
\qquad(N=12)\end{array}$ & $\begin{array}{l}\text { Obese } \\
(N=15)\end{array}$ & $\begin{array}{l}\text { Normal Weight } \\
\qquad(\mathrm{N}=33)\end{array}$ & P-Value \\
\hline \multicolumn{5}{|l|}{ Mean age at diagnosis } \\
\hline$<10$ years & $6(50 \%)$ & $10(66.6 \%)$ & $16(48.5 \%)$ & 0.527 \\
\hline$>10$ years & $6(50 \%)$ & $5(33.3 \%)$ & $17(51.5 \%)$ & 0.527 \\
\hline Hyperlipidemia & $5(41.7 \%)$ & $7(46.6 \%)$ & $4(12.1 \%)$ & 0.001 \\
\hline Short stature & $1(8.3 \%)$ & $1(8.3 \%)$ & $0(0 \%)$ & 0.593 \\
\hline Thyroid disorders & $1(8.3 \%)$ & $0(0 \%)$ & $2(6.06 \%)$ & 1.3 \\
\hline Hypertension & $1(8.3 \%)$ & $1(8.3 \%)$ & $0(0 \%)$ & 0.517 \\
\hline
\end{tabular}


In this study hypertension and cardiac systolic dysfunction was diagnosed in 2 (3.3\%) of patients. It could be due to anthracycline toxicity especially at young age. ${ }^{11}$ This small number of cardiac complication could be due to moderate dose of antracycline and relatively short duration of follow up of 2 years. It is known that after anthracyclineinduced cardiomyopathy, the heart compensates for about $5-15$ years. ${ }^{11}$

The limitations in our study was short period of follow up as compared to other studies. ${ }^{7,21}$ Secondary malignancies like basal cell carcinoma and soft tissue sarcomas which usually take at least 10 years to develop may not be well documented. Therefore, longer follow up of cancer survivors should be performed.

\section{CONCLUSION}

Endocrine and cardiac complications are common among survivors of childhood ALL. We report high prevalence $(56.6 \%)$ of these complications from south Punjab. This could be due to effects of chemotherapy. Therefore extended follow up of ALL survivors is needed in order to identify an abnormality and timely treatment and improved quality of life.

\section{Copyright@ 06 Aug, 2020.}

\section{REFERENCES}

1. Cooper SL, Brown PA. Treatment of pediatric acute lymphoblastic leukemia. Pediatr Clin North Am. 2015; 62(1):61-73.

2. Zuckerman T, Rowe JM. Pathogenesis and prognostication in acute lymphoblastic leukemia. F1000 Prime Rep. 2014 ;6:59.

3. Koka A, Saygin C, Uzunaslan D, Ozdemir N, Apak $\mathrm{H}$, Celkan T. A 17-year experience with ALL-BFM protocol in acute lymphoblastic leukemia: Prognostic predictors and interruptions during protocol. Leuk Res. 2014; 38(6):699-705.

4. Steliarova-Foucher E, Colombet M, Ries LAG, Moreno $F$, Dolya $A$, Bray $F$, et al. International incidence of childhood cancer, 2001-10: A population-based registry study. Lancet Oncol. 2017; 18:719.

5. Yasmeen N, Ashraf S. Childhood acute lymphoblastic leukaemia; Epidemiology and clinicopathological features. J Pak Med Assoc. 2009; 59(3):150-3.
6. Shabbir A Childhood cancers: Experience at a tertiary care hospital. J Rawalpindi Med Coll. 2011; 15: 38-9.

7. Pui, C. H., Mullighan, C. G., Evans, W. E. \& Relling, M. V. Pediatric acute lymphoblastic leukemia: Where are we going and how do we get there? Blood 2012; 120 , 1165-74.

8. Diller L, Chow EJ, Gurney GJ, Hudson MM, KadinLottick NS, Kawashima TI, et al. Chronic disease in the Childhood Cancer Survivor Study Cohort: A review of published findings. Journal of Clinical Oncology, 2009; 27 2339-55.

9. Nathan PC, Wasilewski-Masker K, Janzen LA. Longterm outcomes in survivors of childhood acute Iymphoblastic leukemia. Hematol Oncol Clin North Am 2009; 23:1065-82.

10. Brignardello E, Felicetti F, Castiglione A, Chiabotto P, Corrias A, Fagioli F, et al. Endocrine health conditions in adult survivors of childhood cancer: The need for specialized adult focused follow-up clinics. Eur $\mathrm{J}$ Endocrinol. 2013; 168(3):465-72.

11. Lipshultz SE, Lipsitz SR, Sallan SE, Dalton VM, Mone SM, Gelber RD, Colan SD Chronic progressive cardiac dysfunction years after doxorubicin therapy for childhood acute lymphoblastic leukaemia. J Clin Oncol. 2005; 23:2629-36.

12. Hunger SP, Loh ML, Whitlock JA, Winick NJ, Carrol WL, Devidas M, et al. Children's Oncology Group's 2013 blueprint for research: Acute lymphoblastic leukemia. Pediatr Blood Cancer. 2013; 60: 957-63.

13. Centers for Disease Control and Prevention. Growth charts. Atlanta, CDC, 2010. Available at http://www.cdc. gov/ growthcharts/.

14. Greulich WW, Pyle SI. Radiographic atlas of skeletal development of hand and wrist. 2th ed. Stanford, Stanford University Press, 1999.

15. Tanner JM. Current advances in the study of physique. Photogrammetric anthropometry and an androgyny scale. Lancet 1951; 1:574-79.

16. Brämswig J, Dübbers A. Disorders of pubertal development. Dtsch Arztebl Int 2009; 106:295-303.

17. Edouard T, Tauber M. Delayed puberty. Arch Pediatr 2010; 17:195-200. 
18. National High Blood Pressure Education Program Working Group on High Blood Pressure in Children and Adolescents. The fourth report on the diagnosis, evaluation, and treatment of high blood pressure in children and adolescents. The fourth report on the diagnosis, evaluation, and treatment of high blood pressure in children and adolescents. Pediatrics 2004; 114(Suppl 2):555-76.

19. Trujillo ÁM, Linares A, Sarmiento IC. Intensive chemotherapy in children with acute lymphoblastic leukemia. Interim analysis in a referral center in Colombia. Revista de la Facultad de Medicina. 2016; 64(3):417-25.

20. 12. Maaz AU, Badar F, Mahmood T, Al Nassir I. High infection related mortality in Pakistani children with acute lymphoblastic leukemia during remission induction chemotherapy: Review of Data from a single Institution. Journal of Cancer \& Allied Specialties. 201631 ; 2(4).
21. Oeffinger KC, Mertens AC, Sklar CA, Kawashima T, Hudson MM, Meadows AT, Friedman DL, Marina N, Hobbie W, Kadan-Lottick NS, Schwartz CL, Leisenring W, Robison LL; Childhood Cancer Survivor Study. Chronic health conditions in adult survivors of childhood cancer. N Engl J Med 2006; 355:1572-82.

22. Meacham LR, Gurney JG, Mertens AC, Ness KK, Sklar $\mathrm{CA}$, Robison LL, Oeffinger KC. Body mass index in long-term adult survivors of childhood cancer: A report of the childhood cancer survivor study. Cancer 2005; 103:1730- 39.

23. Zhang FF, Rodday AM, Kelly MJ, Must A, MacPherson C, Roberts SB, Saltzman E, Parsons SK. Predictors of being overweight or obese in survivors of pediatric acute lymphoblastic leukemia (ALL). Pediatr Blood Cancer 2014; 61:1263-69.

24. Chow EJ, Friedman DL, Yasui Y, Whitton JA, Stovall M, Robison LL, Sklar CA. Timing of menarche among survivors of childhood acute lymphoblastic leukemia: $A$ report from the childhood cancer survivor study. Pediatr Blood Cancer 2008; 50:854-58.

\begin{tabular}{|c|c|c|c|}
\hline \multicolumn{4}{|c|}{ AUTHORSHIP AND CONTRIBUTION DECLARATION } \\
\hline Sr. \# & Author(s) Full Name & Contribution to the paper & Author(s) Signature \\
\hline 1 & Waqas Imran Khan & $\begin{array}{l}\text { Literature search, Study design, } \\
\text { Data acquisition, Critical review, } \\
\text { Final approval. }\end{array}$ & \\
\hline 2 & Zulfiqar Ali & $\begin{array}{l}\text { Data acquisition, Critical review, } \\
\text { Final approval. }\end{array}$ & zuet \\
\hline 3 & Sohail Arshad & $\begin{array}{l}\text { Data acquisition, Critical review, } \\
\text { Final approval. }\end{array}$ & \\
\hline
\end{tabular}

